\title{
Seasonality and shelter selection by the slipper lobster Scyllarides latus in the southeastern Mediterranean
}

\author{
Ehud Spanier ${ }^{1}$, Moshe Tom ${ }^{2}$, Shmuel Pisanty ${ }^{3}$, Galit Almog ${ }^{1}$ \\ ${ }^{1}$ Center for Maritime Studies and Department of Maritime Civilizations, University of Haifa, Haifa 31999, Israel \\ ${ }^{2}$ Israel Limnological and Oceanographic Research, Haifa 31080, Israel \\ ${ }^{3}$ Fisheries Technology Unit, Israel Ministry of Agriculture, Haifa 31009, Israel
}

\begin{abstract}
Patterns of migration, abundance and shelter selection by Mediterranean slipper lobsters Scyllarides latus were studied in artificial shelters placed on the shallow continental shelf off the coast of Israel. Underwater censuses and tagging experiments over $>3$ yr indicated a seasonal pattern of adult lobster abundance in shallow water. Lobsters' appearance at the site was associated with low water temperature in winter. They disappeared from shallow water in the study area from mid-summer to late fall. Preliminary data of recaptured tagged lobsters suggest that they migrate northwards and to deeper water. Such long-term migration may be triggered by the high, and perhaps unfavorable, mid-summer temperature in the shallow coastal habitats. It is hypothesized that the continuous stay of slipper lobsters in deeper water through late fall may be a physiological/behavioral adaptation to molting occurring in this period. During their stay in shallow water lobsters tended to remain in the artificial shelters complex and its vicinity. They dwelt in shelters during the day and foraged at night, mainly for bivalves, of which some were brought back to dens before daylight. Analysis of lobster recruitment to artificial reefs of different design indicated preference for lower, horizontal dens with small apertures. Habitats rich with such shelters arc very limited along the flat bottoms of the littoral southeastern Mediterranean. Since sheltering in such dens presumably reduces the risk of predation by diurnal predators, it is advantageous for lobsters to return to these preferred sites after short as well as long-term movements.
\end{abstract}

\section{INTRODUCTION}

The slipper lobsters, family Scyllaridae, include several commercially important species (Phillips et al. 1980). Yet the biological and especially the ecological knowledge of scyllarid lobsters is very limited compared to that of clawed, rock and spiny lobsters (families Nephropidae and Palinuridae) (Ford 1980). Research on scyllarid lobsters in the past concentrated on taxonomic and morphological aspects (e.g. Morin \& MacDonald 1984, Holthuis 1985), descriptions of larval and post-larval stages (e.g. Robertson 1969, Lyons 1980, Phillips et al. 1981), and geographical distribution based on data from oceanographic expeditions and fisheries (e.g. Da Franca et al. 1959, 1961, Lyons 1970).

The Mediterranean (locust) slipper lobster Scyllarides latus (Latreille, 1803) is a good example of this lack of ecological knowledge. This relatively large lobster can attain a weight of more than $1 \mathrm{~kg}$ and thus has been fished intensively in its wide distribution range throughout the Mediterranean (Fischer 1973) and Eastern-Central Atlantic (Fischer et al. 1981). Despite the fact that it has become rare in various areas due to overexploitation (Maigret 1978, G. Fredj, Nice, France, pers. comm. 1986), biological studies have been limited to partial analysis of fisheries data and a few laboratory observations (e.g. Saldanha 1979, Martines 1985). The present study is the first to utilize an in situ research approach to investigate ecological aspects of this species.

Data collection associated with behavioral and ecological studies of lobsters in the field is thwarted by the generally large areas of distribution in question as well as additional limitations imposed on scientists by the hostile marine environment. Several investigators have utilized the fact that many lobsters forage during the night and dwell in shelters during the day - they constructed underwater artificial structures to which lobsters recruited. This enabled some of the difficulties to be overcome in several behavioral-ecological studies 
of lobsters (e.g. Davis 1985, Zimmer-Faust et al. 1985). The technique of constructing artificial shelters was also used in the present study for the investigation of abundance, migration patterns and shelter selection in Scyllarides latus in the southeastern Mediterranean.

\section{MATERIALS AND METHODS}

Four 'reef' units of artificial shelters were constructed of used car tires $(32 \mathrm{~cm}$ inner diameter, $65 \mathrm{~cm}$ outer diameter and $17 \mathrm{~cm}$ tire width) (Fig. 1). The tires were connected with $18 \mathrm{~mm}$ steel bars and each structure was weighted with concrete poured into the lower part of the first row of tires. One unit (Fig. 1A), which will be referred to as the 'S' (square) type, was constructed of
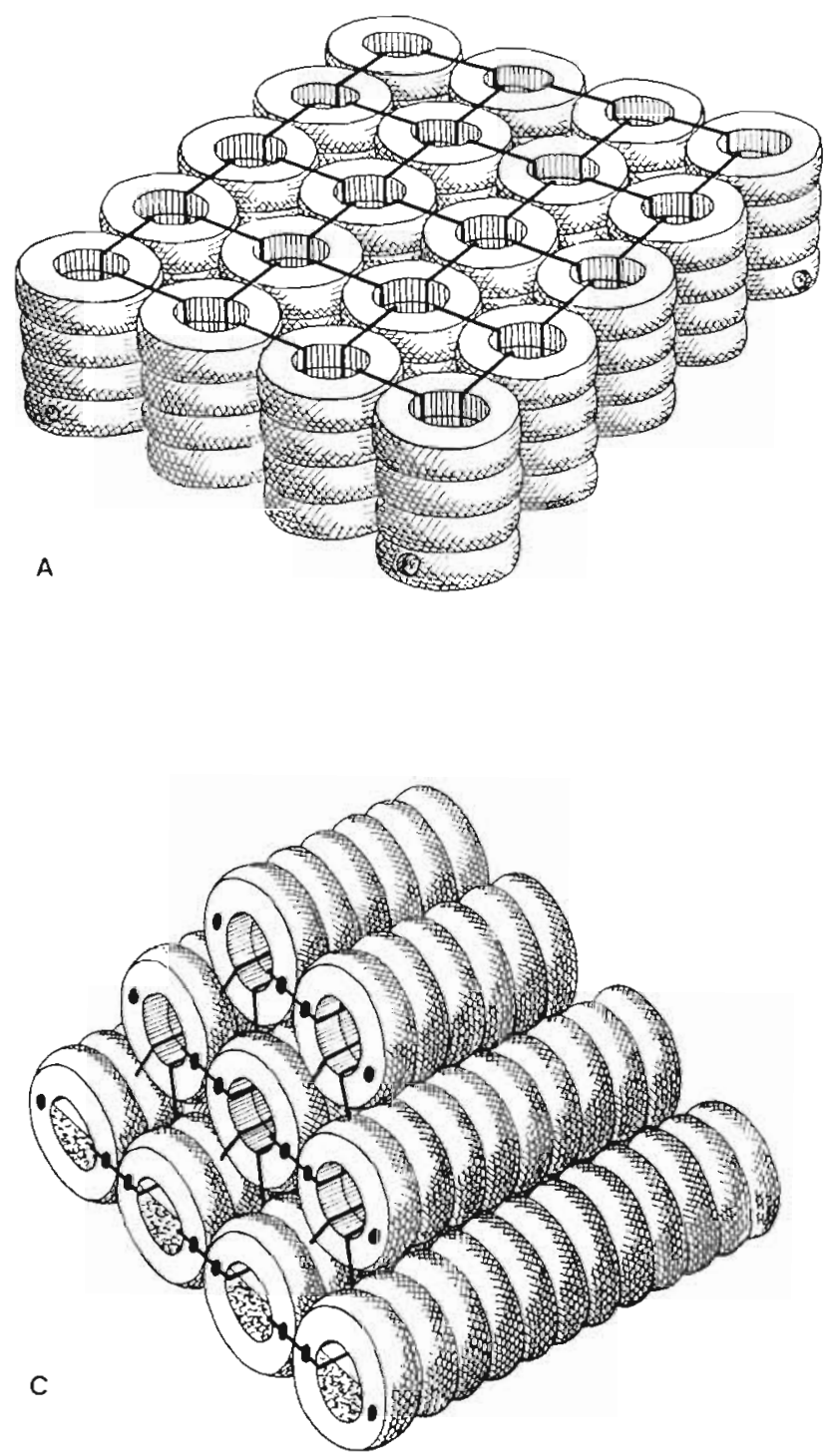

Fig. 1 Schematic representations of artificial shelter units. (A) 'S' type; (B) '5' type; (C) '9' type; (D) 'C' type tubes of tires placed with their broad sides facing the substrate. This arrangement formed large vertical holes (the inner diameter of the tires) as well as small ones (between the tires). The tires of the second unit, the ' 5 ' type (Fig. 1B), were arranged as 5 horizontal tubes in 2 layers. Thus, all the large and small holes of this unit were horizontal. The holes of the third unit, the ' 9 ' type (Fig. 1C), were also in the horizontal plane, but this unit was higher than the ' 5 ' type and consisted of 9 tubes of tires arranged in 3 layers. The last unit, the ' $\mathrm{C}$ ' ('complex') type (Fig. 1D), was similar in size and shape to the ' 9 ' type except that the lower level of tires was rotated $90^{\circ}$ relative to the higher levels and furthermore the upper levels contained less tires with larger spaces between them. In August 1983, these structures were placed 10 to $15 \mathrm{~m}$ apart at a depth of $20 \mathrm{~m}$ southwest of
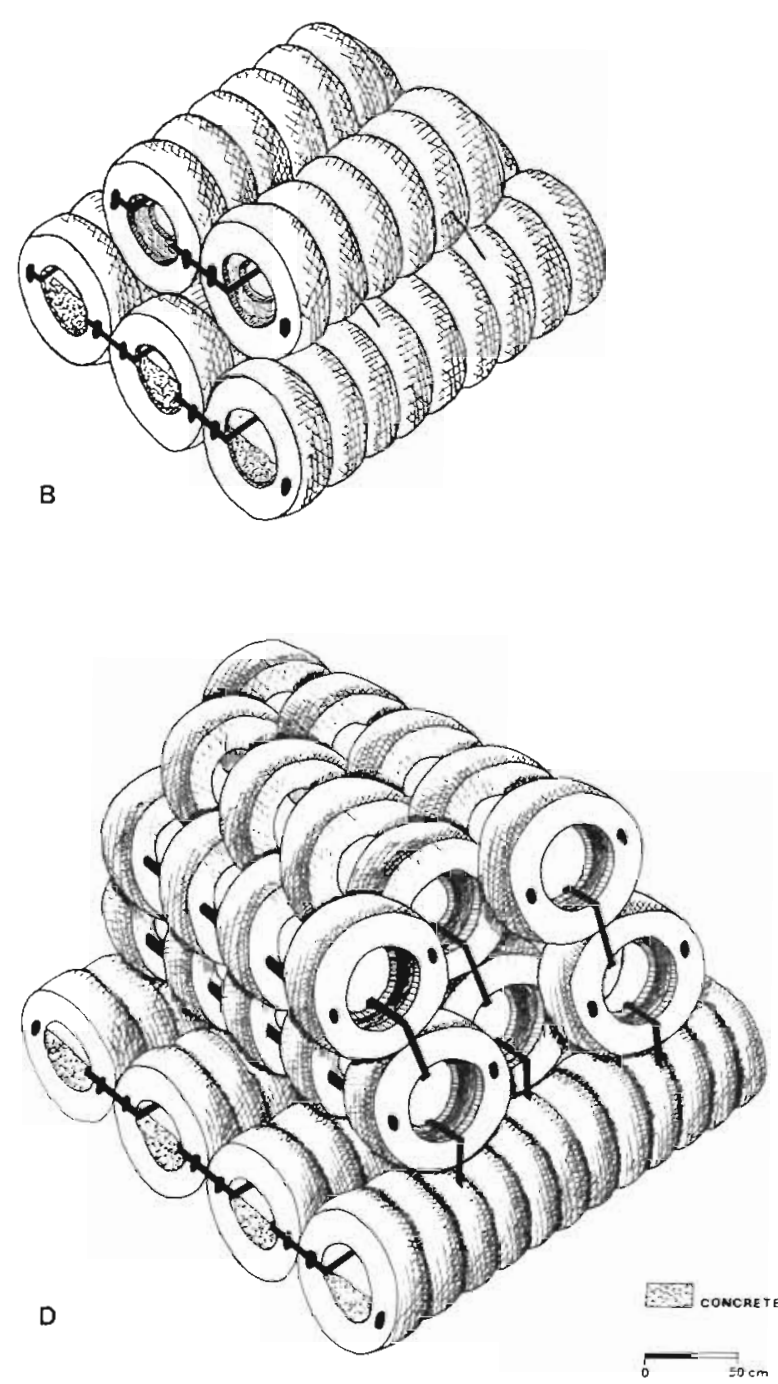
the Israel Institute of Oceanography (Tel Shiqmona), Haifa, Israel (Fig. 2). The bottom at this site is flat consisting of very low biogenic rocks with some coarse calcareous sand.

The site was censused weekly, weather permitting (but at least once a month), by SCUBA divers equipped with underwater flashlights. The location of all lobsters detected in the site was recorded underwater on PVC plates. The lobsters were then caught by hand, sexed and measured for their carapace length (CL: the distance between the tip of the anterior projection and the posterior margins of the carapace) with vernier callipers. The presence of berried females and the colour of the eggs were also recorded. Lobsters were then tagged with numbered plastic 'spaghetti' tags using a

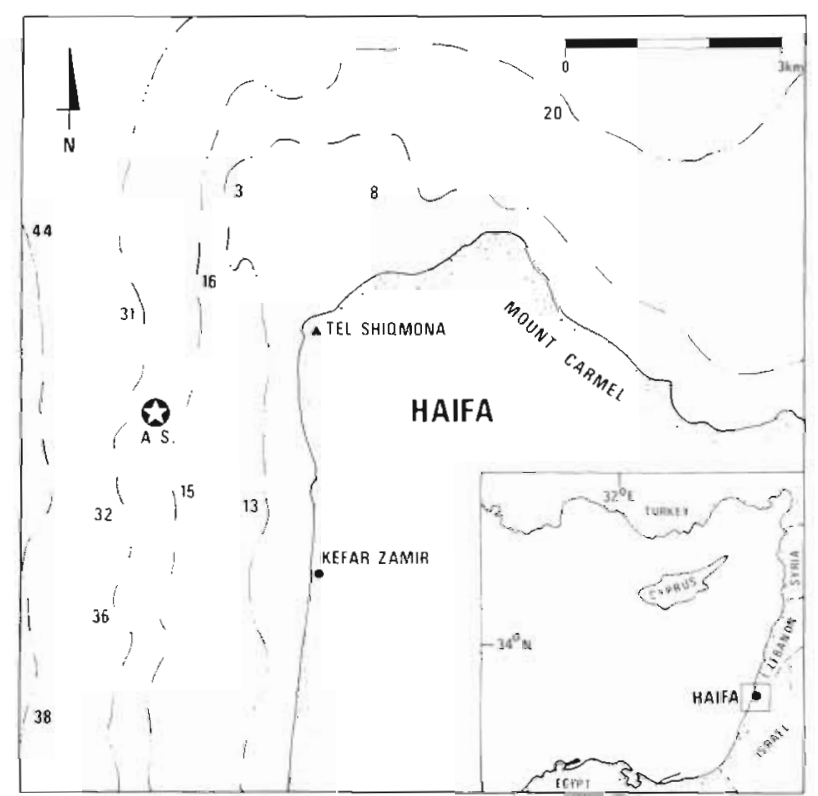

Fig. 2. The study area. A.S.: site of artificial shelters. Water depths in $m$
Mark II tagging gun (Floy Iag Inc., Seattle, WA, USA), equipped with an elongated needle, as well as by puncturing small holes in the telson. Lobsters were released at the site immediately after tagging. The same data were recorded for lobsters recaptured by SCUBA divers and fishermen. Water temperature was measured on each dive at $20 \mathrm{~m}$ depth at the artificial shelter site. Information regarding molting was obtained from fishermen and divers, who reported exuviae found in the field, was well as from molting of lobsters held in tanks in the laboratory. Qualitative data on bivalves found near lobsters in the artificial shelters was also recorded.

\section{RESULTS}

\section{Seasonality}

A total of 433 lobsters Scyllarides latus were recorded in the artificial shelters during the present study between September 1983 and March 1987. The maximum number of lobsters recorded each month and the water temperature in the vicinity of the artificial shelters were compared throughout the study period (Fig. 3). It can be seen that the number of $S$. latus increased rapidly in February-March, peaked in March-May and started dropping toward mid-summer (July-August). From August to late fall (DecemberJanuary) lobsters were usually rare or absent in the artificiai shelters. The seasonal appearance of lobsters in shallow waters is clearly associated with the low winter water temperature in this area. This seasonal pattern was also known from the catches of professional and sport lobster fishermen in natural rocky habitats in Israel (e.g. Table 1). Commercial lobster fishing in the region, mainly by SCUBA technique, is therefore concentrated, between January and June, in
Fig. 3. Scyllarides latus. Maximum number of lobsters detected each month in the artificial shelter site (histograms), and corresponding water temperatures (curve), 1983-1987

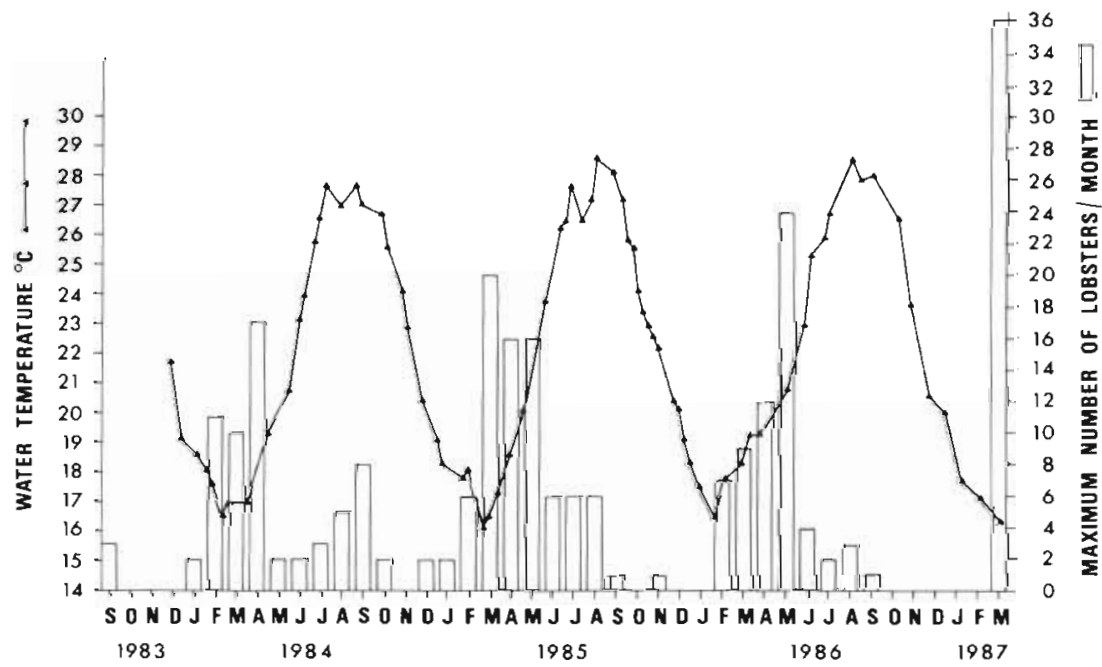


Table 1. Sample of the yield of a commercial lobster fishing unit in one season (1984) in Haifa region. No lobster fishing activities were carried out between June and November

\begin{tabular}{lcccccc}
\hline & Dec & Jan & Feb & Mar & Apr & May \\
\hline $\begin{array}{l}\text { Lobster yield } \\
\left(\mathrm{kg} \mathrm{mo}^{-1}\right)\end{array}$ & 16 & 71.5 & 119.7 & 68.5 & 105.5 & 107.2 \\
$\begin{array}{l}\text { Average daily } \\
\text { lobster yield } \\
\left(\mathrm{kg} \mathrm{d}^{-1}\right)\end{array}$ & 4 & 7.9 & 11.9 & 8.5 & 10.5 & 10.7 \\
\hline
\end{tabular}

water depth 7 to $30 \mathrm{~m}$. Recently a tendency has been observed for lobsters to appear successively in lobster fisheries from north to south along the coast of Israel. In 1987 lobsters appeared in the Akhziv area $(32 \mathrm{~km}$ north of the present study site) in January; at the study site and in Haifa Bay they appeared in late February-early March; in Caesarea, $37 \mathrm{~km}$ south of the study site, they were detected only at the end of March.

Scyllarides latus are usually not caught by trawlers in deeper water because these fishing vessels operate on soft substrate. However, there is one record of lobsters caught by a fishing boat operating a rough bottom trawl at a depth of $60 \mathrm{~m}$ off the coast of northern Israel during October 1985.

All lobsters caught by us, as well as by fishermen, were adults with CL not less than $74 \mathrm{~mm}$. Males ranged up to $125 \mathrm{~mm} \mathrm{CL}$ (mean $96.7 \mathrm{~mm}, \mathrm{SD} 14.1 \mathrm{~mm}$ ) and females up to $139 \mathrm{~mm}$ CL (mean $100.9 \mathrm{~mm}$, SD 12.4 $\mathrm{mm}$ ). The ratio of females to males was $52: 48$.

Males and females with white gelatinous spermatophores near the genital pores were observed from April. Ovigerous females with orange egg masses were observed from May to July after which lobsters started disappearing from shallow waters.

\section{Residence time and migration}

Altogether 190 lobsters were tagged and released; 59 $(31.1 \%)$ of them were recaptured at least once. All except 5 had retained the spaghetti tags when recaptured (the others were identified by the holes punctured in their telson). Sixteen of the tagged specimens $(8.4 \%)$ were caught twice and 5 lobsters $(2.6 \%)$ were caught 3 times. Most recaptured lobsters (69.5\%) were detected in the artificial shelters site repeatedly during the season (January to July; see Fig. 3). Time between repeat captures varied from 1 wk to 4 mo (average 29.3 d). Nine of the tagged lobsters $(4.7 \%)$ were recaptured in the same artificial shelters site after a longer period, from 10 mo to $3 \mathrm{yr}$ and $1 \mathrm{mo}$ (average $382.7 \mathrm{~d}$ ). Males constituted $55 \%$ of the total number of recaptured tagged specimens. Only 6 marked lobsters were reported outside of the artificial shelters site. Four were caught by divers operating 300 to $800 \mathrm{~m}$ west and east of the site. A tagged lobster was caught by a trawler operating 20 to $30 \mathrm{~km}$ north of the site in July, $2 \frac{1}{2} \mathrm{mo}$ after being tagged. Another lobster was caught by a diver $25 \mathrm{~km}$ north of the site - this one had lost its spaghetti tag and could only be identified by the holes in its telson.

\section{Molting}

Molting occurred mainly in the early winter. Exuviae were found in the field from November to January (also one in late July). Most moltings in the laboratory (21 out of 25) occurred between the end of October and the beginning of February. Ambient water temperature associated with molting was $17.2^{\circ} \mathrm{C}$ to $19.4^{\circ} \mathrm{C}$. There is one record of an extremely small exuvia (CL $38 \mathrm{~mm}$ ) found at $15 \mathrm{~m}$ water depth.

\section{Shelter selection}

Analysis of shelter selection by lobsters was performed in 3 categories, associated with the morphological characteristics of the reef units. These were: size of the shelter opening (hole diameter: small or large); direction (hole direction: horizontal or vertical) and distance of shelters from the substrate (level in the reef: 1st, 2nd, 3rd). Finally, the selection of lobsters between the 4 artificial reef types (' 5 ', ' 9 ', ' $C$ ' and ' $S$ ') (see Fig. 1) was analysed. The selection of alternatives in the various categories is expressed as the percentage of holes occupied by lobsters. This value was calculated as follows:

$\%$ holes occupied by lobsters $=$

$\frac{\text { total no. of lobsters observed in a given category }}{\text { total no. of units in this category } \times \text { no. of obs. (d) }} \times 100$.

Significance level was determined by using a $G$-test for goodness of fit (Sokal \& Rohlf 1981).

Lobsters significantly selected small holes on shelters over larger openings (Fig. 4). They also showed significant preference for horizontal shelters to those arranged vertically (Fig. 4). They significantly selected small holes in the 2 lower levels of the artificial reefs over shelters with the same opening diameters located in the highest, third level of the reef (Fig. 5). Although a much smaller percentage of shelters with large openings were occupied by lobsters, there was also a clear preference for the 2 lower levels in this category. In fact, no lobsters were observed in shelters with large openings in the upper (third) level of the reef during the present study (Fig. 5). When the various characteristics of shelters are combined in the analysis of lobsters' selection for reef type (Fig 6), significant preference for the '5' type 


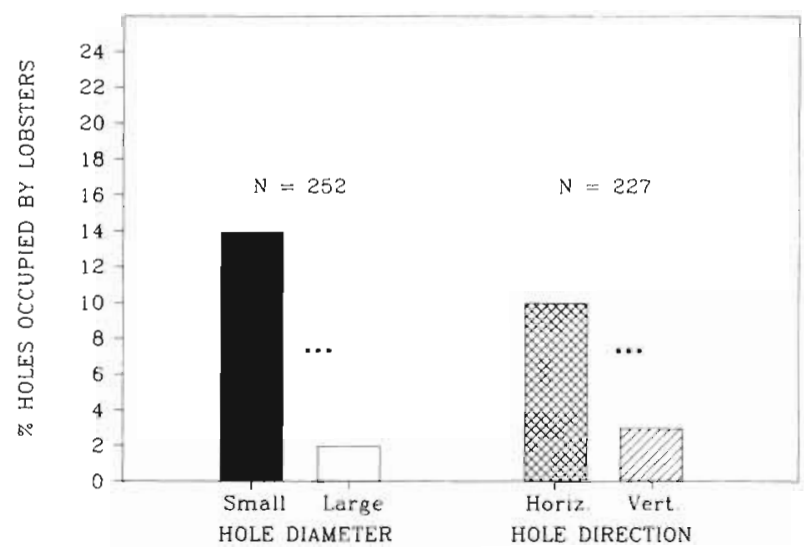

Fig. 4. Scyllarides latus. Shelter selection of lobsters in the artificial reef: preference for size of shelter opening (left) and shelter direction (right). $\mathrm{N}$ : number of individuals observed. Significance was determined using a G-test for goodness of fit. $\cdots p<0.005$

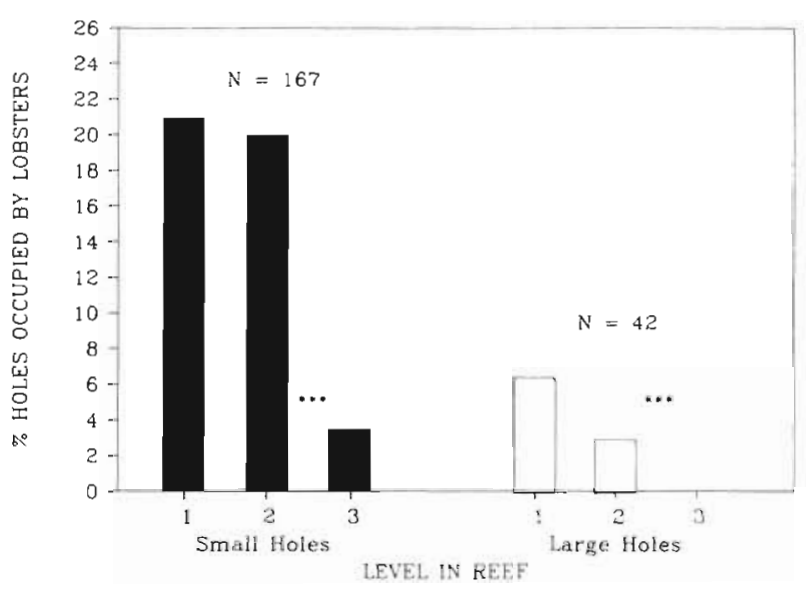

Fig. 5. Scyllarides latus. Shelter selection of lobsters: preference for shelters in different levels in the artificial reefs Analysis was done separately for small (left) and large (right) holes. N: number of individuals observed. Significance was determined using a $G$-test for goodness of fit. $\cdots p<0.005$

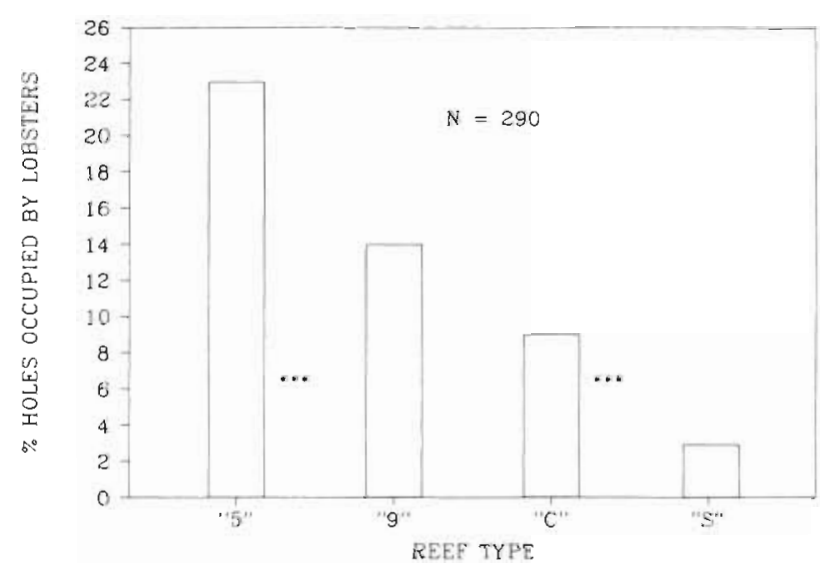

Fig. 6. Scyllarides latus. Shelter selection of lobsters: preference for the different types of artificial reefs. $N$ : number of individuals observed. Significance was determined using a $G$ test for goodness of fit. $\cdots p<0.005$ emerges. The shelters in the ' 9 ' and ' $C$ ' type units were similarly selected by lobsters which significantly preferred them to the vertical 'S' type reef (Fig. 6).

\section{Food}

In season, when lobsters were abundant in the artificial shelters site, live and opened bivalves were found in shelters inhabited by lobsters during the day in all levels of the reefs. The predominant species were Glycymeris pilosus and Venus verrucosa, specimens of which were also carried around and readily consumed by lobsters held in the laboratory. When divers collected all bivalves from the artificial reefs during the season, new clams were detected in shelters occupied by lobsters several days later. Out of the lobsters' season very few bivalves were observed in the artificial shelter site.

\section{DISCUSSION}

The seasonal appearance of adult Scyllarides latus in the shallow continental shelf of the southeastern Mediterranean, as demonstrated in the present study (Fig. 3), posed several ecological questions. Where do adult lobsters stay from August to January? What is the reason for the seasonal pattern? Where are the juvenile $S$ latus? Two biological studies of this species have been done at the opposite, western edge of its distribution range. Da Franca et al. $(1959,1961)$ sampled their study area, in the coastal waters of the Cape Verde Islands, by using traps. They reported catches of $S$. latus in the shallow coastal waters of this tropical region of the eastern Atlantic during April to Novernber within a temperature range of 21 to $27^{\circ} \mathrm{C}$. Females shed eggs off the Cape Verde Islands between June and August at ambient temperatures of 22 to $25^{\circ} \mathrm{C}$. No information was presented about the locations of these lobsters during the winter (December to March). Martines (1985) studied populations of S. latus in the Azores, northeastern Atlantic. Her data, based on lobsters caught by fishermen in coastal waters (5 to $20 \mathrm{~m}$ deep) off Pico Island, indicated that $S$. latus in the Atlantic migrated to deeper water in October. In her study area, they were found at depths of 70 to $75 \mathrm{~m}$ in January and started approaching shallower waters in May where they occurred in greatest numbers in July. She suggested that the timing of migration corresponded well with reproduction since, in the Azores, it occurred after females shed eggs in August-September. It is interesting to note that the seasonal pattern of abundance in our area precedes that of the Azores by 3 to 4 mo (and is similar in this respect to that observed for the popula- 
tions of the Cape Verde Islands). This may be due to the lower summer temperature in the coastal waters (5 to $20 \mathrm{~m}$ deep) of the Azores, which, according to Martines (pers. comm. 1987) is around $20^{\circ} \mathrm{C}$. Summer water temperatures at $20 \mathrm{~m}$ in the southeastern Mediterranean are much higher (Fig. 3). Reproduction in our study area occurs, therefore, in the spring and early summer when water temperatures are lower ranging from $20^{\circ} \mathrm{C}$ in late April to ca. $26^{\circ} \mathrm{C}$ in July. When water temperature increases in our coastal waters, from midsummer toward fall, lobsters leave the region. In comparison to the Azores there is a great degree of overlapping of the reproductive seasons of populations of $S$. latus in the Cape Verde Islands and in the southeastern Mediterranean which is probably due to the higher water temperatures in the latter 2 regions. Da Franca et al. $(1959,1961)$ did not mention migration patterns, but since they reported catches of these lobsters in shallow waters through November, the migration pattern in the Cape Verde Islands seems more similar to the pattern in the Azores than to that of our region.

Our preliminary and partial data of a few marked lobsters moving in mid-summer at least 20 to $30 \mathrm{~km}$ north of the reef, together with the tendency of lobsters to reappear successively from north to south, and the single catch of lobsters in deeper water in early fall, may indicate the direction of and the reason for their movements. We suggest that from mid-summer Iobsters move to colder water in greater depths and towards the north. This migration may be triggered by the high, and perhaps unfavorable, mid-summer water temperature (up to 28 to $29^{\circ} \mathrm{C}$ ) in our coastal region. Oren $(1970,1972)$ showed that the temperature difference between shallow inshore waters (up to $30 \mathrm{~m}$ ) and deeper waters (>50 $\mathrm{m}$ deep) of the shelf in the study area was 6 to $10 \mathrm{C}^{\circ}$ from mid-summer to fall. Thus, lobsters dwelling at $60 \mathrm{~m}$ depth in October are exposed to water temperatures of ca $20^{\circ} \mathrm{C}$ instead of ca $26^{\circ} \mathrm{C}$ at $20 \mathrm{~m}$. This difference decreases at the end of fall and is nil in January. From January through March inshore water temperatures are very similar in all depths from the surface to at least $125 \mathrm{~m}$ (Oren 1972). During this time they fall to their lowest value, under $17^{\circ} \mathrm{C}$. We suggest that this lowest water temperature triggers the return movements of lobsters to shallow water. Another possible cue may be, as indicated in other species (e.g. Hermkind 1985), photoperiodicity. Catching Iobsters by traps placed in the vicinity of deep rocky outcrops in late summer and fall, which is planned for the continuation of this study, may confirm the first hypothesis: a catch of lobsters in traps placed at $48 \mathrm{~m}$ depth at the beginning of October 1987 (water temperature $23.6^{\circ} \mathrm{C}$ ), at a time when no lobsters were detected in the shallow water habitats (water temperature at $20 \mathrm{~m}$ depth, $27.7^{\circ} \mathrm{C}$ ), may be the first indication of this trend.
The small increase in the number of lobsters at the study site in September 1984 remains unexplained.

The physiological reason for the slipper lobsters migration is not clear. Several large marine decapods undergo migration and fulfill a variety of biological functions such as avoiding predators, finding mates, ovary maturation, care of offspring and improving larval recruitment (e.g. reviews by Herrnkind 1983, Rebach 1983). Campbell (1986) studied migratory movements of ovigerous American lobsters. He found positive correlations between change in depth, distance moved and water temperature. He suggested seasonal depth migration to be associated with the proper temperature for completion of egg development. It is difficult to assess the likelihood of a similar association of seasonal movement of Scyllarides latus with the reproductive season in the southeastern Mediterranean. It is not clear yet whether ovigerous female slipper lobsters migrate to deeper water off our coast before egg shedding takes place. The fact that seasonal migration is not limited to females does not support the association of such movements and development of eggs.

The lack of ecological studies on scyllarid lobsters forces us to consider whether other data, such as from spiny lobsters, can shed light on the problem of scyllarid migration. Palinurids, despite their superficial dissimilarity from species of Scyllaridae, share, as Lyons (1970) correctly pointed out, many characteristics with slipper lobsters such as the phyllosoma larva, larval dispersal strategy and sheltering behavior. Some spiny lobsters show migration associated with breeding and release of larvae close to oceanic currents allowing favorable distribution to juvenile nursery grounds (e.g. Moore \& MacFarlane 1984, Booth 1986, MacFarlane \& Moore 1986). Unfortunately, there is no record at all of live juvenile Scyllarides latus in the southeastern Mediterranean and information on larval stages such as phyllosama in plankton sampled in the eastern Mediterranean is scanty (e.g. Pasteur et al. 1976). Thus, there is no data, at present, to allow examination of a similar hypothesis for $S$. latus in the southeastern Mediterranean

Cooper \& Uzman (1980) hypothesized that one possible function of seasonal shallow-deep migrations of lobsters on the continental shelf was to meet physiological requirements for molting. Since Scyllarides latus molt in early winter before they return to shallow water this hypothesis may also fit their environmental requirements. Molting in deeper habitats may also be associated with the avoidance of predators during such a vulnerable period.

The differential shelter selection by slipper lobsters (Figs. 4 to 6) supports the assumption that diurnal sheltering may reduce their vulnerability to diumally 
active predators. Slipper lobsters are not equipped with powerful claws like Nephropid lobsters and do not even possess spines like Palinuridae which use their spinose antennae to fend off diurnally active predators (Zimmer-Faust et al. 1985, Zimmer-Faust \& Spanier 1987). In the absence of morphological adaptations for active defence, sheltering behavior remains the only defence mechanism of slipper lobsters against diurnal predators. They select, therefore, dens which increase their physical protection and reduce their visual detection by such predators. They show preference for dens with smaller apertures (Fig. 4) which prevent the penetration of large predators into their shelter. Smaller shelter openings and horizontal arrangements, which they preferred (Fig. 4), keep low light levels in the shelters, placed in the relatively clear water of the eastern Mediterranean. The combination of shade and the cryptic color of scyllarid lobsters (see also Ogren 1977) make them very difficult to detect. The lobsters strong tendency towards shady areas was demonstrated by the behavior of tagged lobsters released underwater. They immediately moved to the closest shady area which was frequently between the diver's legs. Their sheltering and their gregarious behavior (details to be published elsewhere), as observed in artificial shelters, was also detected in natural rocky habitats. There they also showed clear preference for naturally occurring dens with the same physical characteristics (i.e. small openings, horizontal, close to the bottom). Spiny lobsters, which possess limited active defence adaptations, demonstrate similar preference for shelters and gregariousness (Spanier \& Zimmer-Faust 1986, Zimmer-Faust \& Spanier 1987). The preference of slipper lobsters for shelter in the lower level of the reef (Fig. 5) may be associated with their benthic habit. Additionally, higher dwelling may mean increased exposure to detection and predation by freeswimming predators.

When considering all the physical characteristics of artificial shelters combined (Fig. 6) there is clear preference for the ' 5 ' type reef. From the standpoint of lobsters fishery ecology this structure is the most effective in recruiting lobsters due to the horizontal arrangement of shelters and their proximity to the substrate. The ' 9 ' and ' $C$ ' reef types are somewhat less efficient for sheltering lobsters because of the rare use of their upper part by these crustaceans. The ' $S$ ' type reef had the lowest percentage of holes occupied by lobsters, presumably due to the vertical orientation of the shelters allowing more light to penetrate from the surface.

It is not clear what is the main predator(s) of Scyllarides latus (other than man). Ogren (1977) and Martines (1985) mentioned sharks and large fish, such as the grouper, as potential predators of scyllarids. Sharks were very rare in the study area. Large grou- pers of the species Epinephelus guaza and E. alexandrinus were very common in the artificial reefs. However, they were observed frequently with lobsters in the same hole with no apparent predator-prey interactions. The absence of lobster remains in the stomach contents of large groupers caught in the reef during the lobster season also exclude them as predators of $S$. latus. Large Octopus vulgaris were detected in the artificial reefs and its vicinity and we suggest considering them as potential predators of $S$. latus. Ambrose \& Nelson (1983) studied predation by $O$, vulgaris in shallow waters off the French Mediterranean coast. They reported $20 \%$ of the prey discards near the $O$. vulgaris shelter as those of unidentified crustaceans. Beside the lack of final identification, it is questionable whether these remains were of $S$. latus due to the shallow depth $(<10 \mathrm{~m})$ and the overfishing of slipper lobsters in that area (see 'Introduction'). Guerra (1978) collected $O$. vulgaris at depths of 15 to $100 \mathrm{~m}$ in the Mediterranean and reported a predominantly crustacean diet for this cephalopod. A detailed analysis of this type of prey might have revealed the remains of $S$. latus. Octopuses were reported as natural predators of several other species of lobsters (Phillips et al. 1980) and Joll (1977) showed Octopus tetricus as a major predator of pot-caught Panulirus cygnus in Western Australia.

Our observations and tagging data indicate that lobsters returned repeatedly to the same artificial shelter site during the season. They left their shelter at night while periorming short-term movements to forage and bring back bivalves to the site. Perhaps this is an indication of 'squirrel-like' food storage behavior (Sherry 1985). Another explanation, suggested by a reviewer of this paper, is that bivalves are brought back to the den so that the lobster can consume them in the protected surroundings of the shelter. The recapturing of only some of the tagged lobsters at the site during the season may also be explained by local nomadism (Herrnkind 1983). Lobsters leave the artificial reef from mid-summer, and at least some of them return to the same small artificial reef after longer periods which is presumably associated with long-term migration. Why and how do they perform this return movement? The flat bottom of the continental shelf of the southeastern Mediterranean are poor in natural habitats, such as submerged sandstone ('kurkar') ridges (Adler 1985), which supply preferred dens for lobsters. Since sheltering in such dens presumably reduces the risk of predation by diurnal predators, it is advantageous for lobsters to recall these preferred sites and to return to them after short as well as long-term movements as indicated in the present study. The physiological mechanism which enables the relocation of such a small site in the open sea, especially after long-term migration, is not yet 
known in slipper lobsters. The findings associated with magnetic field detection in the western Atlantic spiny lobster (Lohmann 1984) call for investigation of this sensory channel also in connection with the navigation of the Mediterranean slipper lobster.

Acknowledgements. The authors express their gratitude to Y. Tur-Caspa and S. Breitstein for their valuable aid in underwater operations. Appreciation is directed to E. Grofit for his assistance in organizing various facets of the project. Dr S. Berenstein, R. Pollak and Z. Fridman are acknowledged for their help in preparing the figures. This study was supported in part by the Center for Maritime Studies, University of Haifa and the Fisheries Technology Unit, Israel Ministry of Agriculture.

\section{LITERATURE CITED}

Adler, E. (1985). The submerged kurkar ridges off the northern Carmel coast. M. A. thesis, University of Haifa, Israel (Hebrew)

Ambrose, R. F., Nelson, B. V. (1983). Predation by Octopus vulgaris in the Mediterranean. P.S.Z.N.I. Mar. Ecol, 4: $251-261$

Booth, J. D. (1986). Recruitment of packhorse rock lobster Jasus verreauxi in New Zealand. Can. J. Fish. Aquat. Sci. 43: 2212-2220

Campbell, A. (1986). Migratory movement of ovigerous lobsters, Homarus americanus, tagged off Grand Manan, eastern Canada. J. Fish. Res. Bd Can. 43: 2197-2205

Cooper, R. A., Uzman, J. R. (1980). Ecology of juvenile and adult Homarus. In: Cobb, J. S., Phillips, B. F. (eds.) Biology and management of lobsters, Vol. II. Academic Press, New York, p. 97-142

Da Franca, P., Paes Da Franca, M., Da Costa, F. C. (1959) Contribuição para o conhecimento das lagostas do arquipélago de Cabo Verde. Notas mimeografadas do Centro Biologia Piscatória 6: 1-21

Da Franca, P., Paes Da Franca, M. L. (1961). Nova contribuiçāo para o conhecimento das lagostas do arquipélago de Cabo Verde. Notas mimeografadas do Centro Biologia Piscatória 19: $1-17$

Davis, G. E. (1985). Artificial structures to mitigate marine construction impacts on spiny lobsters, Panulirus argus. Bull. mar. Sci. 37: 151-156

Fischer, W. (1973). FAO species identification sheets for fishery purposes. Mediterranean and Black Sea (fishing area 37), Vol. 2. Food and Agricultural Organization, Rome

Fischer, W., Bianchi, G., Scott, W. B. (1981). FAO species identification sheets for fishery purposes. Eastern Central Atlantic (fishing areas 34,47 in part), Vol. 5. Department of Fisheries and Oceans, Canada, Ottawa

Ford, R. F. (1980). Introduction. In: Cobb, J. S., Phillips, B. F (eds.) The biology and management of lobsters, Vol. II. Ecology and management. Academic Press, New York, p. $3-9$

Guerra, A. (1978). Sobre la alimentacion y el comportamiento alımentario de Octopus vulgaris. Invest. Pesq 42: 351-364

Herrnkind, W. F. (1983). Movement patterns and orientation. In: Bliss, D. E. (ed.) The biology of crustacea, Vol. VII. Academic Press, New York, p. 41-105

Herrnkind, W F. (1985). Evolution and mechanisms of mass singlefile migration in spiny lobsters. In: Rankin, M. A. (ed.) Migration: mechanisms and adaptive significance. Contr. Mar. Sci. 15 (Suppl.): 197-211
Holthuis, L. B. (1985). A revision of the family scyllaridae (Crustacea: Decapoda, Macrura). I. Subfamily Ibacinae. Zool. Verh., Leiden 218: 1-130

Joll, L. M. (1977). The predation of pot-caught western rock lobster (Panulirus longipes cygnus) by octopus. West. Aust. Fish. Wild Rep. 29: 1-11

Lohmann, K. J. (1984). Magnetic remanence in the western Atlantic spiny lobster, Panulirus argus. J. exp. Biol. 113 . $29-41$

Lyons, W. G. (1970). Scyllarid lobsters (Crustacea, Decapoda). Mem. Hourglass Cruises 1: 1-74

Lyons, W. G. (1980). The postlarval stages of scyllaridean lobsters. Fisheries 5: $47-49$

MacFarlane, J. W., Moore, R. (1986). Reproduction of the ornate rock lobster, Panulirus ornatus (Fabricius), in Papua New Guinea. Aust. J. mar. Freshwat. Res. 37: 55-65

Maigret, J. (1978). Contribution à l'étude des langoustes de la côte occidentale d'Afrique (Crustacés, Décapodes, Palinuridae) 5. Les larves phyllosomes de Scyllaridae et de Palinuridae recueillies au large des côtes du Sahara. Bull. Inst. fond. Afr. noire 40: 36-80

Martines, H. R. (1985). Biological studies of the exploited stock of the Mediterranean Iocust lobster Scyllarides latus (Latreille, 1803) (Decapoda: Scyllaridae) in the Azores. J. crust. Biol. 5: 294-305

Moore, R., MacFarlane, J. W. (1984). Migration of the ornate rock lobster, Panulirus ornatus (Fabricius), in Papua New Guinea. Aust. J. mar. Freshwat. Res. 35: 197-212

Morin, T D., MacDonald, C. D. (1984). Occurrence of the slipper lobster, Scyllarides haanii in the Hawaiian Archipelago. Proc. biol. Soc. Wash. 97: 404-407

Ogren, L. H. (1977). Concealment behavior of the Spanish lobster, Scyllarides nodifer (Stimpson), with observations on its diel activity. Northeast Gulf Sci. 1; 115-116

Oren, O. H. (1970). Chemical and physical changes in the Mediterranean waters off Israel and the problem of production in low trophic levels. Sea Fish. Res. Sta. Haifa. (Mimeo)

Oren, O. H., Hornung, H. (1972). Temperatures and salinities off the Israel Mediterranean coast. Sea Fish. Res. Sta. Haifa 59: $17-31$

Pasteur, R., Berdugo, V., Kimor, B. (1976). The abundance, composition and seasonal distribution of epizooplankton in coastal and offshore waters of the eastern Mediterranean. Acta adriat. 28: 55-80

Phillips, B. F., Brown, P. A., Rimmer, D. W., Braine, S. J. (1981). Description, distribution and abundance of the late larval stages of the Scyllaridae (slipper lobsters) in the Southeastem Indian Ocean. Aust. J. mar. Freshwat. Res. 32: 417-437

Phillips, B. F., Cobb, J. S., George, R. W. (1980). General biology. In: Cobb, J. S., Phillips, B. F. (eds.) The biology and management of lobsters, Vol. I, Physiology and behavior. Academic Press, New York, p. 1-82

Rebach, S. (1983). Orientation and migration in Crustacea. In: Rebach, S., Dunham, D. W. (eds.) Studies in adaptation, the behavior of higher crustacea. John Wiley \& Son, New York, p. 217-264

Robertson, P. B. (1969). The early larval development of the scyllarid Iobster Scyllarides aequinoctialis (Lund) in the laboratory, with a revision of the larval characters of the genus. Deep Sea Res. 16:557-586

Saldanha, L. (1979). Dados sobre o cavaco (Scyllarides latus). Missáo Bio-oceanográfica Acores. 79: 14-18 (Mimeo)

Sherry, D. F. (1985). Food storage by birds and mammals. Adv. Study Behav. 15: 153-188

Sokal, R. R., Rohlf, F. G. (1981). Biometry. W. H. Freeman, New York 
Spanier, E., Zimmer-Faust, R. K. (1986). Evidence for conspecific attraction influencing den selection by spiny lobsters. Proc. Ann. Conf. Animal Behavior Society of America, Tucson, p. 2

Zimmer-Faust, R. K., Spanier, E. (1987). Gregariousness and sociality in spiny lobsters: implications for den habitation. J. exp. mar. Biol. Ecol. 105: 57-71
Zimmer-Faust, R. K., Tyre, J. E., Case, J. F. (1985). Chemical attraction causing aggregation in the spiny lobster, Panulirus interruptus (Randall), and its probable ecological significance. Biol. Bull. mar. biol. Lab., Woods Hole 169: $106-118$

This article was presented by Professor T Berman; it was accepted for printing on December 8, 1987 